\title{
Получение и свойства термоэлектрического материала на основе $\mathrm{Zn}_{4} \mathrm{Sb}_{3}$
}

\author{
(C) В.П. Панченко ${ }^{1,2}$, Н.Ю. Табачкова ${ }^{2}$, А.А. Иванов ${ }^{1}$, Б.Р. Сенатулин ${ }^{2}$, Е.А. Андреев ${ }^{2}$ \\ ${ }^{1}$ ОАО „Гиредмет“, \\ 119017 Москва, Россия \\ ${ }^{2}$ Национальный исследовательский технологический университет „МИСиС“, \\ 119079 Москва, Россия \\ E-mail: vppanchenko@mail.ru
}

(Получена 12 декабря 2016 г. Принята к печати 19 декабря 2016 г.)

\begin{abstract}
Проведено исследование влияния условий синтеза на структуру и термоэлектрические свойства материалов на основе антимонида цинка. Рассмотрены вопросы влияния избыточного $\mathrm{Zn}$, режимов искрового плазменного спекания и легирования In на фазовый состав и термостабильность свойств полученного материала. Материал получали методом прямого сплавления компонентов и методом искрового плазменного спекания. Показано, что при определенных режимах искрового плазменного спекания введение избыточного количества $\mathrm{Zn}$ и легирование In позволяют получить материал $\beta-\mathrm{Zn}_{4} \mathrm{Sb}_{3}$ со значением термоэлектрической эффективности $Z T \approx 1.47$ при температуре $720 \mathrm{~K}$, который показал стабильность свойств в рамках проведенных испытаний.
\end{abstract}

DOI: 10.21883/FTP.2017.06.44549.08

\section{1. Введение}

Соединение $\mathrm{ZnSb}$ давно известно и широко применялось в СССР в 50-е годы в качестве материала для положительных ветвей термоэлектрических генераторов типа ТГК-1, ТГК-3 и ТГК-2-2-ТЭГ [1], но с разработкой более эффективной системы твердых растворов $\mathrm{Bi}_{2} \mathrm{Te}_{3}-\mathrm{Sb}_{2} \mathrm{Te}_{3}$ использовать $\mathrm{ZnSb}$ перестали. Новый интерес к материалам на основе антимонида цинка появился после того, как в 1997 г. Лаборатория реактивного движения (НАСА) опубликовала работу, в которой в связи с поиском новых высокоэффективных термоэлектрических материалов была изучена система $\mathrm{Zn}-\mathrm{Sb}$ [2]. В данной системе были подробно исследованы и описаны свойства фазы $\beta-\mathrm{Zn}_{4} \mathrm{Sb}_{3}$, а также сообщалось о фазах $\mathrm{ZnSb}$ и $\mathrm{Zn}_{3} \mathrm{Sb}_{2}$.

Фаза $\beta-\mathrm{Zn}_{4} \mathrm{Sb}_{3}$ существует в области температур $263-765 \mathrm{~K}$, характеризуется значительной долей разупорядоченности: 20\% атомов $\mathrm{Zn}$ расположены в трех различных междоузлиях. Эти межузельные атомы создают значительные локальные искажения решетки и очень подвижны (скорость диффузии Zn почти такая же, как в суперионных проводниках) [3]. Следствием структурного разупорядочения является низкая решеточная теплопроводность $\beta-\mathrm{Zn}_{4} \mathrm{Sb}_{3}$ и соответственно возможность получения высоких значений термоэлектрической добротности. Однако одной из главных проблем является нестабильность этого материала при нагреве до $765 \mathrm{~K}$ даже в инертной атмосфере [4].

Цель работы - исследование влияния условий синтеза на структуру, термоэлектрические свойства и стабильность полученных характеристик в материалах на основе антимонида цинка.

\section{2. Методика эксперимента}

Соединения на основе $\mathrm{Zn}_{4} \mathrm{Sb}_{3}$ синтезировали методом прямого сплавления компонентов при температуре $1023 \mathrm{~K}$ в течение 2 ч с последующей закалкой в ледяной воде. Синтезированный материал измельчали до размера частиц < 40 мкм. Объемные образцы получали методом искрового плазменного спекания (ИПС) при следующих режимах: температура $673 \mathrm{~K}$, давление 40 или 100 МПа, время выдержки при температуре спекания 5 или 10 мин.

Температурные зависимости электропроводности, термоэдс, температуропроводности и теплоемкости измеряли в циклах „нагрев-последующее охлаждение“ в интервале температур 300-723-400 К. Электропроводность и термоэдс измеряли на установке ZEM 3 (Ulvac, Япония). Теплопроводность рассчитывали по формуле $\lambda=D_{t} C_{p} d$, где $D_{t}-$ температуропроводность, $C_{p}-$ удельная теплоемкость, $d-$ плотность. Температуропроводность и удельную теплоемкость измеряли методами лазерной вспышки на установках LFA 457 (Netzsch, Германия) и дифференциальной сканирующей калориметрии DSC-404C (Netzsch, Германия) соответственно. Плотность образцов измеряли методом Архимеда. Фазовый анализ проводили методом рентгеновской дифрактометрии на установке Bruker D8 (Германия).

\section{3. Экспериментальные результаты}

При синтезе соединения $\mathrm{Zn}_{4} \mathrm{Sb}_{3}$ методом прямого сплавления компонентов, взятых в стехиометрическом мольном соотношении $[\mathrm{Zn}] /[\mathrm{Sb}]=4 / 3$, получили материал, содержащий две фазы - $\beta-\mathrm{Zn}_{4} \mathrm{Sb}_{3}$ и $\mathrm{ZnSb}$. Проведение синтеза с добавлением избыточного цинка в количестве $2.5 \%$ (здесь и далее указаны массовые доли) 

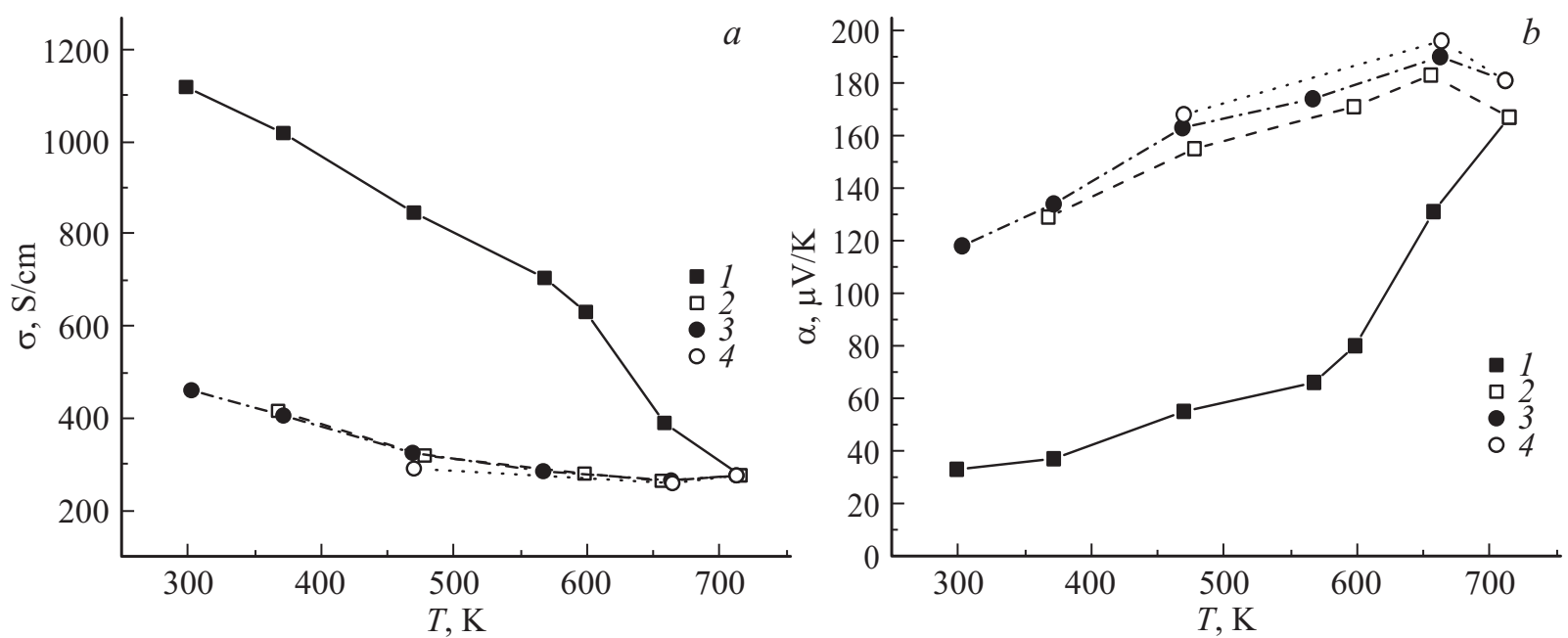

Рис. 1. Изменение электропроводности $\sigma(a)$ и термоэдс $\alpha(b)$ в процессе циклирования температуры в образцах $\mathrm{Zn}_{4} \mathrm{Sb}_{3}+2.5 \% \mathrm{Zn}: 1$ - нагрев в 1-м цикле, 2 - охлаждение в 1-м цикле, 3 - нагрев во 2-м цикле, 4 - охлаждение во 2 -м цикле.

не изменило фазовый состав материала, но повлияло на формирование структуры при последующем искровом плазменном спекании. При компактировании образцов методом ИПС при температуре $673 \mathrm{~K}$, в течение 10 мин, при давлении $40 \mathrm{MПа} \mathrm{из} \mathrm{порошков} \mathrm{синтезированного}$ материала без избытка $\mathrm{Zn}$ получили однофазный материал $\mathrm{ZnSb}$. Компактирование материала из порошков синтезированного материала с избытком Zn при таких же условиях спекания позволило получить материал, в основном содержащий фазу $\mathrm{Zn}_{4} \mathrm{Sb}_{3}$. Изменение фазового состава наблюдали только в тонких слоях на поверхности образца. С одной стороны образца кроме фазы $\mathrm{Zn}_{4} \mathrm{Sb}_{3}$ наблюдали присутствие $\mathrm{Zn}$. С другой стороны образца слой $\sim 50$ мкм содержал только фазу $\mathrm{ZnSb}$. Так как спекание методом ИПС осуществляется пропусканием импульсного электрического тока через компактируемый материал, мы полагаем, что с пропусканием электрического тока происходила электромиграция ионов цинка к катоду. Это привело к образованию слоя, содержащего избыточный цинк на поверхности образца со стороны катода, и к образованию обедненного цинком слоя, а именно $\mathrm{ZnSb}$, на поверхности образца со стороны анода. Для уменьшения разложения в ходе компактирования методом ИПС мы увеличили прикладываемое давление к спекаемому материалу с 40 до 100 МПа. В результате пиковое значение пропускаемого электрического тока упало с 630 до $420 \mathrm{~A}$, а среднее значение тока уменьшилось с 600 до 370 А. Время выдержки при температуре спекания уменьшили с 10 до 5 мин. Это позволило получить однофазный материал $\mathrm{Zn}_{4} \mathrm{Sb}_{3}$ во всем объеме образца.

Дальнейшие исследования структуры и свойств проводили только на полученном материале $\mathrm{Zn}_{4} \mathrm{Sb}_{3}$, так как этот материал обладает большей величиной термоэлектрической эффективности, чем $\mathrm{ZnSb}$, и представляет интерес как реальный материал для термоэлектрических генераторов, работающих в диапазоне температур $500-765 \mathrm{~K}$.

Измерения электропроводности и термоэдс образцов $\beta-\mathrm{Zn}_{4} \mathrm{Sb}_{3}$ проводились в процессе циклирования температуры от комнатной до $723 \mathrm{~K}$. Уже в ходе 1-го цикла наблюдалось резкое падение электропроводности и рост термоэдс. Выдержка образцов при комнатной температуре и повторные измерения показали, что значения электропроводности и термоэдс не приобрели свои исходные значения (рис. 1).

Фазовый анализ образцов, прошедших циклические исследования термоэлектрических свойств, показал, что при нагреве происходит распад $\beta-\mathrm{Zn}_{4} \mathrm{Sb}_{3} \rightarrow 3 \mathrm{ZnSb}+\mathrm{Zn}$. Такая деградация структуры характерна для фазы $\beta-\mathrm{Zn}_{4} \mathrm{Sb}_{3}$ и связана с переходом атомов цинка из межузельных позиций (характерных для фазы $\beta-\mathrm{Zn}_{4} \mathrm{Sb}_{3}$ ) в позиции решетки: $\mathrm{Zn}_{I} \rightarrow \mathrm{Zn}_{L}$ [5,6].

С целью уменьшения количества атомов цинка, занимающих межузельные позиции в $\beta-\mathrm{Zn}_{4} \mathrm{Sb}_{3}$, провели синтез материала с легирующей добавкой индия. Введение небольших концентраций металла приводит к перераспределению атомов цинка, атомы легирующего металла занимают позиции $\mathrm{Zn}_{I}$ и увеличивают количество атомов цинка в позициях $\mathrm{Zn}_{L}$ [7]. Методом прямого сплавления компонентов были синтезированы образцы составов $\mathrm{Zn}_{3.82} \mathrm{In}_{0.18} \mathrm{Sb}_{3}$ и $\mathrm{Zn}_{3.82} \mathrm{In}_{0.18} \mathrm{Sb}_{3}+2.5 \% \mathrm{Zn}$. Компактирование материала проводили при температуре $673 \mathrm{~K}$, давлении $100 \mathrm{MПа,} \mathrm{в} \mathrm{течение} 5$ мин. Для исследования термостабильности полученного материала были проведены измерения термоэлектрических свойств в процессе циклирования температуры, также были проведены исследования фазового анализа образцов до и после 7 циклов термоциклирования. Фазовый состав образцов, легированных In с избытком и без избытка $\mathrm{Zn}$, после ИПС был одинаковым, образцы содержа- 

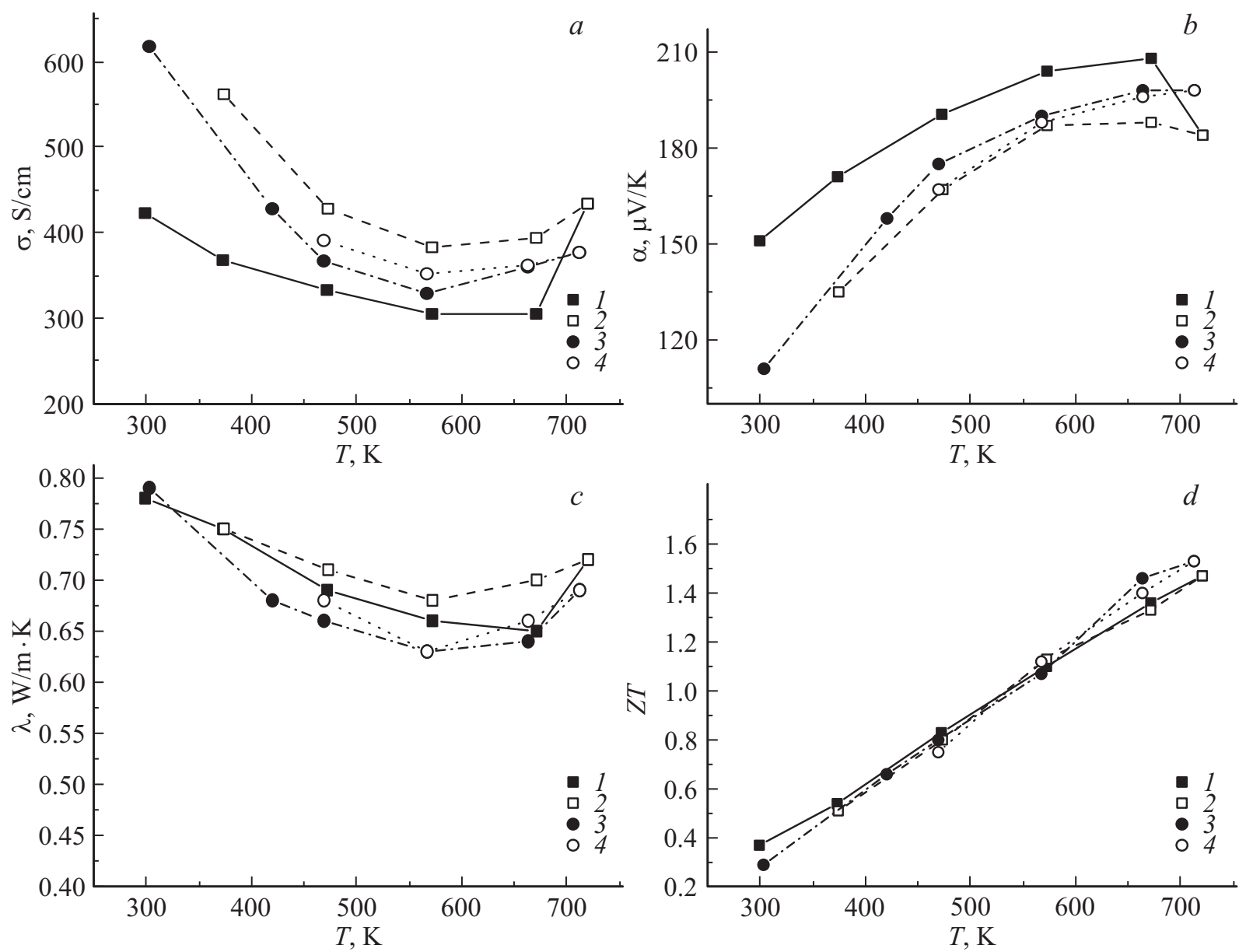

Рис. 2. Зависимости электропроводности $\sigma(a)$, термоэдс $\alpha(b)$, теплопроводности $\lambda(c)$ и термоэлектрической эффективности $Z T(d)$ образцов $\mathrm{Zn}_{3.82} \mathrm{In}_{0.18} \mathrm{Sb}_{3}+2.5 \% \mathrm{Zn}$ при термоциклировании: 1 - нагрев в 1-м цикле, 2 - охлаждение в 1-м цикле, 3 - нагрев в 7-м цикле, 4 - охлаждение в 7-м цикле.

ли только фазу $\beta-\mathrm{Zn}_{4} \mathrm{Sb}_{3}$. После термоциклирования в образцах $\mathrm{Zn}_{3.82} \mathrm{In}_{0.18} \mathrm{Sb}_{3}$, полученных без избытка $\mathrm{Zn}$, произошел частичный распад $\beta-\mathrm{Zn}_{4} \mathrm{Sb}_{3}$. Материал после термоциклирования содержал смесь фаз: $\mathrm{Zn}_{4} \mathrm{Sb}_{3}$, $\mathrm{ZnSb}$ и $\mathrm{InSb}$. В образцах $\mathrm{Zn}_{3.82} \mathrm{In}_{0.18} \mathrm{Sb}_{3}+2.5 \% \mathrm{Zn}$ после термоциклических испытаний помимо основной фазы $\beta-\mathrm{Zn}_{4} \mathrm{Sb}_{3}$ наблюдалось только выделение небольшого количества InSb.

В образцах $\mathrm{Zn}_{3.82} \mathrm{In}_{0.18} \mathrm{Sb}_{3}$ без избытка цинка в ходе 1-го цикла наблюдался гистерезис электропроводности и термоэдс, связанный с процессом термического разложения $\beta-\mathrm{Zn}_{4} \mathrm{Sb}_{3}$, в 7-м цикле величина $\sigma$ в среднем увеличилась на $19 \%$ в сравнении с 1-м циклом, а $\alpha$ уменьшилась на $10 \%$. Величина теплопроводности для образцов $\mathrm{Zn}_{3.82} \mathrm{In}_{0.18} \mathrm{Sb}_{3}$ при температурах $650-723 \mathrm{~K}$ увеличилась в 7-м цикле на 20-30\% по сравнению с 1-м циклом. Как следствие, величина термоэлектрической эффективности $Z T$ изменилась от значения 1.23 до 1.09 при температуре $714 \mathrm{~K}$.

На рис. 2 представлены результаты измерений в 1-м и 7-м циклах для образцов с избыточным содержанием цинка.
В образцах $\mathrm{Zn}_{3.82} \mathrm{In}_{0.18} \mathrm{Sb}_{3}+2.5 \% \mathrm{Zn}$ в 1-м цикле наблюдается небольшой гистерезис электропроводности и термоэдс, в 7-м цикле их величины практически не изменяются. Величина теплопроводности в ходе термоциклирования не изменилась. В результате величина термоэлектрической эффективности в образцах, легированных индием, с избыточным содержанием цинка практически не изменяется и при температуре $720 \mathrm{~K}$ составляет $Z T \approx 1.47$. Таким образом, при определенных режимах ИПС введение избыточного количества $\mathrm{Zn}$ и легирование In позволили получить материал $\beta-\mathrm{Zn}_{4} \mathrm{Sb}_{3}$, который показал стабильность свойств в данных условиях эксперимента.

\section{4. Заключение}

Показано, что методом прямого сплавления компонентов не удалось синтезировать однофазный материал $\mathrm{Zn}_{4} \mathrm{Sb}_{3}$. Требуемая фаза $\beta-\mathrm{Zn}_{4} \mathrm{Sb}_{3}$ получается методом искрового плазменного спекания из синтезированного 
материала, взятого в стехиометрическом мольном соотношении с добавлением избыточного цинка.

Обнаружено электролитическое разложение материала при пропускании импульсов постоянного тока во время искрового плазменного спекания. Увеличение давления спекания до 100 МПа снизило величину пропускаемого электрического тока через материал, что позволило устранить электромиграцию ионов цинка к катоду при искровом плазменном спекании.

Показано влияние легирования In на термоэлектрические свойства и термостабильность $\beta-\mathrm{Zn}_{4} \mathrm{Sb}_{3}$. В ходе термоциклирования максимальное значение термоэлектрической эффективности твердых растворов $\mathrm{Zn}_{3.82} \mathrm{In}_{0.18} \mathrm{Sb}_{3}$ с избыточным содержанием Zn практически не меняется и при температуре $720 \mathrm{~K}$ составляет $Z T \approx 1.47$.

\section{Список литературы}

[1] А.Ф. Иоффе. Полупроводниковые термоэлементы (М.-Л., Изд-во АН СССР, 1960) гл. IV, с. 127.

[2] T. Caillat, J.-P. Fleurial, A. Borshchevsky. J. Phys. Chem. Solids, 58, 1119 (1997).

[3] E.S. Toberer, K.A. Sasaki, C.R.I. Chisholm, S.M. Haile, W.A. Godard III, G.J. Snyder. Phys. Status Solidi RRL, 1, 253 (2007).

[4] B.L. Pedersen, H. Birkedal, P.T. Frederiksen, B.B. Iversen. 25th Intern. Conf. Thermoelectrics Pr. ICT' (Vienna, Austria, 2006) p. 520.

[5] B.B. Iversen. J. Mater. Chem., 20, 10778 (2010).

[6] T. Dasgupta, H. Yin, J. de Boor, C. Stiewe, B.B. Iversen, E. Müller. J. Electron. Mater., 42, 1988 (2013).

[7] D. Thang, W. Zhao, J. Yu, P. Wei, H. Zhou, W. Zhu, Q. Zhang. J. Alloys Comp., 601, 50 (2014).

Редактор Л.В. Шаронова

\section{Preparation and properties of the thermoelectric material based on $\mathbf{Z n}_{4} \mathbf{S b}_{3}$}

V.P. Panchenko ${ }^{1,2}$, N.Yu. Tabachkova ${ }^{2}$, A.A. Ivanov' ${ }^{1}$, B.R. Senatulin², E.A. Andreev²

1 JSC „Giredmet",

119017 Moscow, Russia

${ }^{2}$ National University of Science and Technology

„MISIS“,

119049 Moscow, Russia

Abstract The investigation of the effect of synthesis conditions on the structure and thermoelectric properties of the zink antimony based materials were carried out in this article. Influence of $\mathrm{Zn}$ excess, plasma sintering conditions and In doping on the phase composition and thermal stability properties of the resulting material were considered. The material was prepared by means of direct alloying of components and spark plasma sintering. It is shown that under certain conditions of spark plasma sintering the addition of excessive amount of $\mathrm{Zn}$ and doping by In allows to obtain $\beta-\mathrm{Zn}_{4} \mathrm{SbZ}_{3}$ with the thermoelectric efficiency $Z T \approx 1.47$ at the temperature of $720 \mathrm{~K}$, which showed stability of the characteristic under the tests. 